\title{
Coulisses
}

Revue de théâtre

25 | Hiver 2002

Varia

\section{Ida désœuvrée, un rapport à la vérité}

\author{
Juliette Herdoin
}

\section{(2) OpenEdition}

Journals

Édition électronique

URL : http://journals.openedition.org/coulisses/5946

DOI : $10.4000 /$ coulisses.5946

ISSN : 2546-9460

\section{Éditeur}

Presses universitaires de Franche-Comté

\section{Édition imprimée}

Date de publication : 1 janvier 2002

Pagination : 32

ISBN : 2-84627-052-X

ISSN : $1150-594 \mathrm{X}$

Référence électronique

Juliette Herdoin, « Ida désœuvrée, un rapport à la vérité », Coulisses [En ligne], 25 | Hiver 2002, mis en ligne le 24 octobre 2019, consulté le 15 novembre 2019. URL : http://journals.openedition.org/ coulisses/5946; DOI : 10.4000/coulisses.5946

Ce document a été généré automatiquement le 15 novembre 2019.

Coulisses 


\title{
Ida désœuvrée, un rapport à la vérité
}

\author{
Juliette Herdoin
}

1 Le rythme global du spectacle est très lent... Les néons mettent un temps infini à changer de couleur. Les images de la télévision se mettent en mouvement avec encore plus de lenteur que les mouvements de l'actrice. Tout tend à faire entrer le public dans une sorte d'état hypnotique...

2 Moi-même, assise dans cette petite salle aussi grande que la scène, toute calfeutrée et silencieuse, je m'attendais à m'ennuyer ou à m'endormir. Lorsque la pièce a commencé, je me suis sentie irritée par la lenteur des gestes et me suis demandée si je n'allais pas perdre mon temps. Mais le décor m'intriguait et me plaisait parce qu'il ressemblait à un tableau. Et petit à petit, le jeu de l'actrice, la lenteur provoquant la patience des spectateurs, tout cela m'a plu. Finalement j'ai été subjuguée par la beauté de l'actrice, par sa présence et sa prestance sur scène, par la subtilité des textes, et les messages que j'ai ressentis. Par exemple, lorsqu'Ida déclare que de toute façon: "Qu'on soit ici, ou ailleurs, ou chez soi, c'est la même chose. On ne sera pas forcément mieux ailleurs qu'ici ». Pour moi, c'est un rapport à la vérité que l'homme cherche durant toute sa vie. En effet, des gens passent leur temps à voyager sans obtenir de réponses aux questions de la vie. Cela ne sert à rien; les réponses sont en nous; il faut d'abord apprendre à se connaître soi-même. Voilà ce que les paroles d'Ida ont évoqué en moi. Et c'est pour cela que j'ai lu le livre Ida de Gertrude Stein, et regardé un reportage la concernant.

Mais les spectateurs ne réagissent pas toujours de la même façon. Tout d'abord, certains se sont sentis pris en otage, parce que la sortie étant située à côté de la scène, il n'était donc pas possible de s'éclipser sans être vu. Beaucoup sont restés contre leur volonté et se sont sentis frustrés. Il y a eu aussi de la colère contre un texte senti comme trop provocateur. Par exemple, lorsqu'Ida déclare : «Vraiment si je savais votre nom, vous ne m'intéresseriez pas; et si je ne connais pas votre nom, pas moyen de m'intéresser, certainement pas ». La plupart de ceux qui ont aimé cette pièce sont, soit des amateurs de théâtre moderne, soit des connaisseurs de Gertrude Stein ou de Patrick de Bergen. On peut donc se demander si cette forme de théâtre n'est pas un danger pour ce genre de mise en scène. En effet, les textes proposés ne risquent-ils pas, à force 
d'être mal ressentis, de susciter l'irritation du public et sa désaffection pour le théâtre. Au fil du temps, ce style théâtral ne risque-t-il pas de n'attirer que des connaisseurs au détriment d'un public plus varié?

4 Toutefois, lorsque Picasso, ami de Gertrude Stein, a exposé ses premières toiles, les gens riaient de lui et de ses œuvres... On peut donc penser qu'au fil du temps, et dans une sorte d'apprentissage, les spectateurs finiront par apprécier cette forme de théâtre.

\section{AUTEUR}

\section{JULIETTE HERDOIN}

Étudiante DEUG théâtre, $1^{\text {ère }}$ année 